\title{
Implementasi Model Waterfall Pada Sistem Informasi Akuntansi Penjualan Jasa Service Mobil
}

\author{
Sudirja $^{1}$, Faradillah ${ }^{2}$, Husna Absharina Awanis ${ }^{3}$ \\ 1,2,3 Universitas Bina Sarana Informatika \\ ${ }^{1}$ sudirja.sdj@bsi.ac.id, ${ }^{2}$ fara@gmail.com, ${ }^{3}$ husnaabsharina8418@gmail.com
}

\begin{tabular}{ccc}
\hline Diterima & Direvisi & Disetujui \\
$25-01-2020$ & $02-06-2020$ & $04-06-2020$ \\
\hline
\end{tabular}

\begin{abstract}
Abstrak - Berkembangnya teknologi di sekitar kita telah membawa manfaat bagi kemajuan kehidupan manusia khususnya teknologi informasi yang memudahkan dalam mengakses data dan informasi bagi perusahaan sehingga memperlancar proses pekerjaan untuk meningkatkan pelayanan pelanggan. Dalam dunia otomotif, salah satu pelayanan yang penting bagi kendaraan adalah perawatan mobil yang sering disebut dengan bengkel mobil, salah satunya PT Bintang Sekata Mandiri Jakarta yang melayani jasa perbaikan cat mobil. Namun, seluruh proses bisnis di bengkel ini masih dilakukan secara manual, atau belum terkomputerisasi, mulai dari proses pengajuan service sampai pembuatan laporan dan penyimpanan dokumen yang berhubungan dengan proses penjualan jasa service, sehingga memungkinkan terjadinya kesalahan dalam pencatatan serta kehilangan ataupun kerusakan dokumen. Perancangan sistem informasi ini merupakan salah satu solusi untuk menyelesaikan masalah yang ada di bengkel ini. Metodologi yang digunakan dalam perancangan sistem informasi penjualan ini adalah metode pengembangan perangkat lunak model air terjun (waterfall) yang menggunakan sistem database. Diharapkan dengan adanya sistem informasi penjualan ini dapat membantu dalam penyimpanan data sehingga dalam proses pencarian, pencatatan, pengolahan menjadi lebih mudah, efektif dan efisien.
\end{abstract}

Kata Kunci: Waterfall, Sistem Informasi Akuntansi, Penjualan Jasa

\begin{abstract}
The technology development around us gives many advatages to the advancement of human life, especially information technology which eases us to access data and information for companies so that the work process can run smoother to increase customers satisfaction. In automobile businesses, one of the most important services is car garage, and one of the companies giving this service is PT Bintang Sekata Mandiri Jakarta which specializes themselves in car paint repairing. However, all work processes in this garage is still done manually, or uncomputerized, from submitting service care, making reports, until keeping documents related to service sales. Thereore, the possibilities in making mistakes is greater on recording and filing documents. One of the solutions to this garage is designing an information system using database method. The proposed methodology is called waterfall software model. It is expected that this database information system can help the company to keep sales data in order to make the search, record, and transaction process easier, more effective and efficient.
\end{abstract}

Keyword: Waterfall, System Information Accounting, Service Sales

\section{PENDAHULUAN}

Tidak dapat dipungkiri berkembangnya teknologi di sekitar kita telah membawa manfaat bagi kemajuan kehidupan manusia khususnya teknologi informasi yang memudahkan dalam mengakses data dan informasi bagi penggunanya. Hal ini sangat didukung untuk kelancaran suatu proses pekerjaan karena hampir disetiap perusahaan, organisasi, lembaga maupun instansi memerlukan pengaksesan data dan informasi yang cepat dan efisien dalam upaya peningkatan pelayanan terhadap pelanggan. Setiap perusahaan dalam menjalankan usahanya pasti mempunyai tujuan yang berbeda antara satu dengan yang lainnya tetapi, pada umumnya perusahaan mempunyai tujuan untuk memperoleh laba atas hasil usaha yang dijalankan. Dalam mencapai tujuannya, perusahaan harus memiliki suatu sistem yang dapat digunakaan untuk merencanakan, menyusun, mengelola, melaksanakan, dan mengawasi aktivitas perusahaan tersebut. Sistem perusahaan yang baik dapat menunjang keberhasilan dan kemajuan perusahaan seperti sistem informasi akuntansi.

Maka dari itu SIA menjadi salah satu faktor penentu kesuksesan perusahaan. Dalam dunia otomotif, salah satu pelayanan yang penting bagi kendaraan adalah perawatan mobil yang sering disebut dengan bengkel mobil. Bisnis bengkel mobil pun bukan hanya bertumpu pada kegiatan jasa pelayanan perawatan mobil saja, namun ada faktor - 
faktor tertentu yang memang mampu mendukung kegiatan bisnis ini, seperti contohnya memiliki fasilitas tempat yang cukup nyaman, pelayanan kepada pelanggan yang baik dan memuaskan, dan juga untuk mempertahankan kelangsungan bisnisnya harus ditunjang dengan suatu sistem yang baik, baik pembukuan, pencatatan atau dari bidang manajemen yang handal. Dalam jurnal (Model, Pada, Gian, \& Autoservice, 2019), peluang usaha ini dimanfaatkan oleh para pemilik modal untuk mendirikan perusahaan jasa bengkel yang menawarkan produk berupa jasa perawatan atau service kendaraan khususnya mobil. Salah satu perusahaan yang mengembangkan usahanya pada pelayanan jasa perawatan mobil atau usaha service body-repair mobil adalah PT Bintang Sekata Mandiri Jakarta yang melayani perbaikan cat mobil. Dalam kegiatan seluruh transaksinya masih dicatat secara manual seperti catatan estimasi harga, surat perintah kerja (SPK) dan laporan penjualannya pun masih dicatat dalam bentuk microsoft excel, hal tersebut yang menjadikan format output tidak standar dan penyimpanan dokumen tidak teratur sehingga dapat mengakibatkan dokumen mudah hilang.

\section{METODE PENELITIAN}

Untuk mendapatkan data-data yang akurat, peneliti melakukan observasi di bagian penjualan dan finance PT Bintang Sekata Mandiri untuk mengetahui secara langsung proses bisnis yang berjalan saat ini, mulai dari proses pendaftaran sampai dengan proses pembuatan laporan penjualan dan laporan keuangan. Hal ini dimaksudkan untuk mengetahui permasalahan yang dihadapi pada PT Bintang Sekata Mandiri terutama di bagian penjualan dan finance. Selain melakukan observasi peneliti juga mengadakan wawancara secara langsung kepada pimpinan yang ada di bagian penjualan dan finance.

Menurut (Sukamto \& Shalahuddin, 2014) menjelaskan tentang metode pengembangan sistem yaitu waterfall. Metode air terjun (waterfall) sering disebut metode sekuensial linier (sequential linear) atau alur hidup klasik (classic life cycle). Model air terjun menyediakan pendekatan alur hidup terurut mulai dari analisis, desain, pengkodean, pengujian, dan pemeliharaan.

Metode yang digunakan pada pengembangan perangkat lunak ini menggunakan model waterfall dalam buku (Sukamto \& Shalahuddin, 2014), yaitu:

1. Analisis kebutuhan software

Proses pengumpulan kebutuhan untuk menspesifikasikan kebutuhan perangkat lunak agar dapat dipahami perangkat lunak seperti apa yang dibutuhkan oleh user serta menganalisa kebutuhan dokumen masukan maupun dokumen keluaran.

2. Desain

Desain perangkat lunak adalah proses multi langkah yang fokus pada desain pembuatan program perangkat lunak termasuk struktur data, arsitektur perangkat lunak, representasi antarmuka, dan prosedur pengodean. Dalam tahapan ini digambarkan dengan rancangan UML (Unified Modeling Language) yang diantaranya ada Use Case Diagram, Activity Diagram, Component Diagram, dan Deployment Diagra. Serta untuk mendesain database penulis menggunakan ERD.

3. Code Generation

Dalam pembuatan coding untuk memperindah tampilan dan mendesain tampilan semua diterjemahkan kedalam program perangkat lunak seperti NetBeans IDE 8.2 dan XAMPP sebagai servernya.

4. Testing

Untuk pengujian terhadap program penjualan jasa service dilakukan dengan menggunakan metode black box testing, yang dilakukan dengan tujuan memastikan output yang dihasilkan sesuai dengan inputan, dan validasi yang dibuat untuk program.

5. Support

Program penjualan jasa service yang dirancang ini tidak menutup kemungkinan mengalami perubahan ketika digunakan oleh pihak bengkel. Maka diperlukan beberapa faktor pendukung seperti pemasangan antivirus dan membuat salinan data agar tidak mudah hilang.

\section{HASIL DAN PEMBAHASAN}

\section{A. Hasil Analisis Kebutuhan Software}

Analisa kebutuhan software merupakan hasil dari data yang telah dilakukan pengamatan tentang permasalah yang telah dihadapi oleh PT Bintang Sekata Mandiri Jakarta dalam pengolahan data penjualan jasa service. Adapun analisa kebutuhan software akan dijelaskan dengan analisa kebutuhan Use Case Diagram dan Activity Diagram.

Peneliti telah mengidentifikasikan kebutuhan yang diperoleh berdasarkan kebutuhan pengguna dan sistem, yaitu :

1. Analisis Kebutuhan Administrator

a. Administrator dapat melakukan Login

b. Administrator dapat mengelola Data Akun

c. Administrator dapat mengelola Data Pelanggan

d. Administrator dapat mengelola Paket Service

e. Administrator dapat mengelola Pendaftaran

f. Administrator dapat mengelola Status

g. Administrator dapat mengelola Pembayaran

h. Administrator dapat mengelola Jurnal Umum

i. Administrator dapat mengelola Laporan Penjualan Service

j. Administrator dapat melakukan Logout 


\section{Analisa Kebutuhan Bagian Keuangan}

a. Bagian Keuangan dapat melakukan Login

b. Bagian Keuangan dapat mengelola Data Akun

c. Bagian Keuangan dapat mengelola Jurnal Umum

d. Bagian Keuangan dapat mengelola Laporan Penjualan Service

e. Bagian Keuangan dapat melakukan Logout

3. Analisis Kebutuhan Staff
a. Staff dapat melakukan Login
b. Staff dapat mengelola Data Pelanggan
c. Staff dapat mengelola Paket Service
d. Staff dapat mengelola Pendaftaran
e. Staff dapat mengelola Status
f. Staff dapat mengelola Pembayaran
g. Staff dapat melakukan Logout

\section{B. Desain Sistem}

1. Desain hak akses penggunaan sistem informasi akuntansi penjualan jasa service mobil. Desain Akses Pengguna Sistem dapat dilihat pada Gambar 1.

2. Desain aktivitas sistem informasi akuntansi penjualan jasa service mobil. Rancangan Aktivitas system dapat dilihat pada Gambar 2.

3. Desain Database Sistem Informasi Akuntansi Penjualan Jasa Service Mobil.

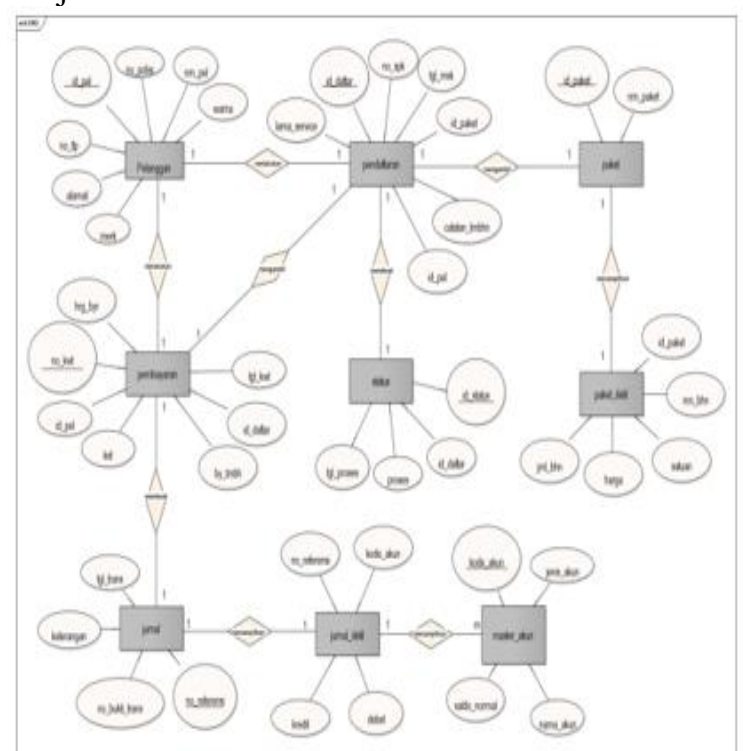

Sumber: Hasil Penelitian (2019)

Gambar 3. Rancangan Database Sistem
4. Desain User Interface

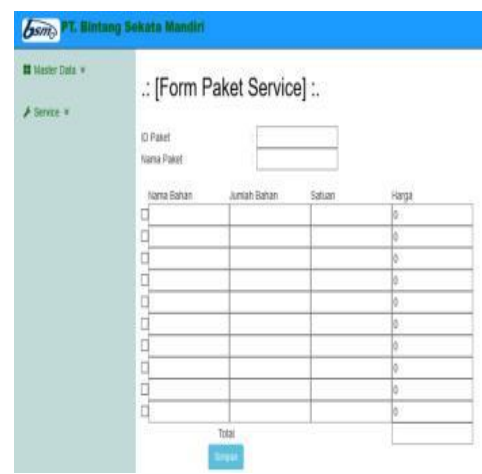

Sumber: Hasil Penelitian (2019)

Gambar 4. Desain User Interface Paket Service

Untuk menginput form paket service yang hanya bisa dikelola oleh bagian administrator ini dimulai dari mengklik menu master data kemudian klik lagi submenu master data yaitu paket service lalu klik tambah paket service dan sistem akan menampilkan form paket service seperti gambar yang ada dibawah ini, setelah menginput semua data maka bagian administrator mengklik simpan dan otomatis data akan tersimpan didalam database. Selain action simpan, ada juga action edit, hapus, cari dan cetak paket service.

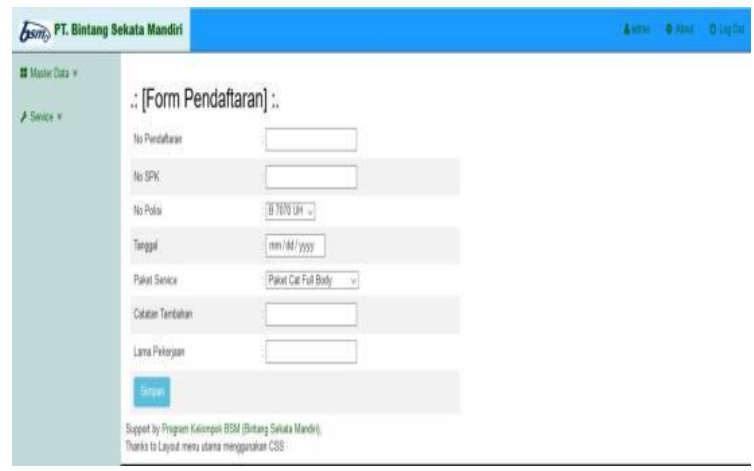

Sumber: Hasil Penelitian (2019)

Gambar 5. Desain User Interface Pendaftaran

Untuk menginput form pendaftaran yang hanya bisa dikelola oleh bagian administrator ini dimulai dari mengklik menu service kemudian klik lagi submenu service yaitu pendaftaran lalu klik tambah data pendaftaran dan sistem akan menampilkan form pendaftaran seperti gambar yang ada dibawah ini, setelah menginput semua data maka bagian administrator mengklik simpan dan otomatis data akan tersimpan didalam database. Selain action simpan, ada juga action edit, hapus, cari dan cetak data pendaftaran. 


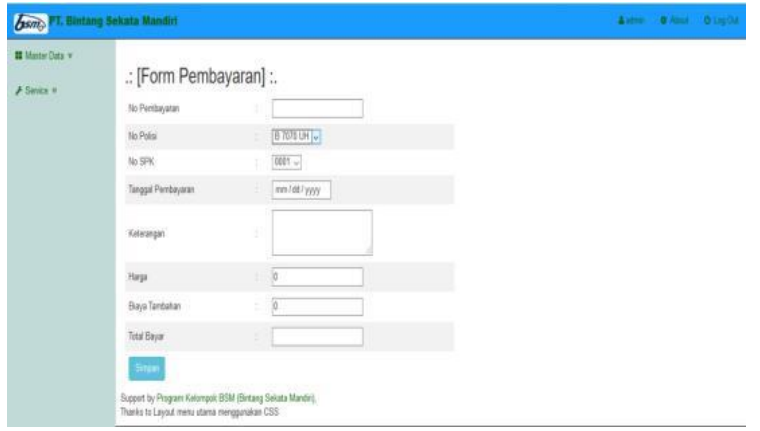

Sumber: Hasil Penelitian (2019)

Gambar 6. Desain User Interface Transaksi Pembayaran

Untuk menginput form pembayaran yang hanya bisa dikelola oleh bagian administrator ini dimulai dari mengklik menu service kemudian klik lagi submenu service yaitu pembayaran lalu klik tambah data pembayaran dan sistem akan menampilkan form pembayaran seperti gambar yang ada dibawah ini, setelah menginput semua data maka bagian administrator mengklik simpan dan otomatis data akan tersimpan didalam database. Selain action simpan, ada juga action cari dan cetak data pembayaran.

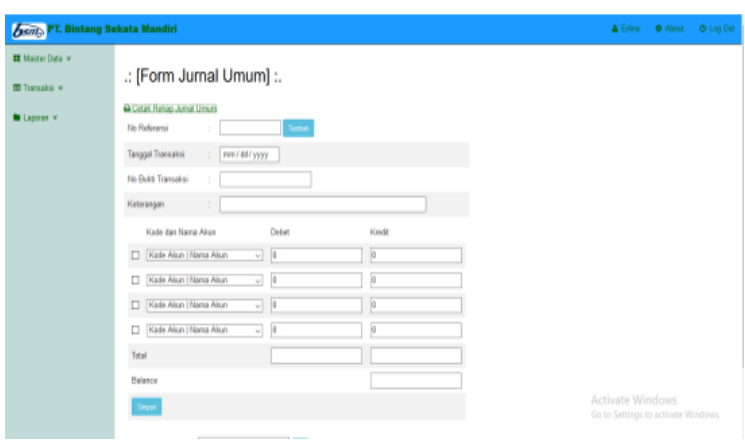

Sumber: Hasil Penelitian (2019)

Gambar 7. Desain User Interface Posting Jurnal

Untuk menginput form jurnal umum yang hanya bisa dikelola oleh bagian keuangan ini dimulai dari mengklik menu transaksi kemudian klik lagi submenu transaksi yaitu jurnal umum lalu klik tambah jurnal umum dan sistem akan menampilkan form jurnal umum seperti gambar yang ada dibawah ini, setelah menginput semua data maka bagian keuangan mengklik simpan dan otomatis data akan tersimpan didalam database. Selain action simpan, ada juga action cari dan cetak data jurnal umum.

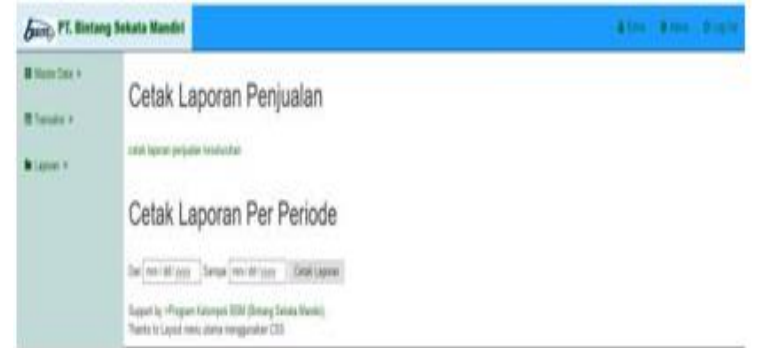

Sumber: Hasil Penelitian (2019)

Gambar 8. Desain User Interface Cetak Laporan

Didalam menu laporan ini terdapat submenu laporan yaitu laporan penjualan service yang hanya bisa dikelola oleh bagian keuangan saja untuk dicetak.

\section{KESIMPULAN}

Dengan adanya sistem penjualan jasa service yang sudah terkomputerisasi ini menjadi lebih efektif dan efesien, dapat menghemat waktu dan tempat, dan mengurangi masalah-masalah yang timbul karena proses kerja yang masih manual sehingga sistem penjualan jasa service di PT Bintang Sekata Mandiri Jakarta lebih terkontrol.

Dengan adanya sistem informasi penjualan jasa service ini dapat membantu mempermudah karyawan dalam proses mendapatkan informasi dan pengelolaan data penjualan jasa service sehingga membuat pelayanan terhadap pelanggan menjadi lebih efektif dan efisien.

Keamanan data lebih terjamin karena adanya user login dan database sehingga tidak semua orang dapat menginput, merubah atau menghapus data.

\section{REFERENSI}

Di, I., Yuppentek, S. M. K., \& Tangerang, C. (2016). Perancangan Media Video Profile Berbentuk Promosi Dan Informasi Di Smk Yuppentek 4. 2(1), 1-11.

Harjunawati, S. (2016). Sistem informasi akuntansi penjualan berbasis waterfall model untuk perusahaan dagang. 1(2), 44-53.

Hutahean, J. (2015). Konsep Sistem Informasi. Yogyakarta: Deepublish.

Informasi, P. S. (2016). Akademik Berbasis Web. (1), 91-99.

Journal, I., \& Engineering, S. (2016). Kata kunci : sistem informasi, penjadwalan, berbasis web. 2(1), 31-38.

Junianto, E., \& Primaesha, Y. (2015). Perancangan Sistem Tracking Invoice Laboraturium Pada Pt Sucufindo ( Persero ) Bandung. II(2), 442-452.

Kadir, A. (2014). Pengenalan Sistem Informasi. Yogyakarta: Andi Offset.

Kasus, S., Asman, P., Yogyakarta, N., Hutapea, L., Muningsih, E., \& Bsi, A. (2017). Implementasi Informasi Pembayaran Kredit Berbasis Web. 
6(1), 11-16.

Kotler, P., \& Keller, K. L. (2016). Marketing Management, 15th Edition New Jersey. Pearson Pretice Hall.

Krismaji. (2015). Sistem Informasi Akuntansi. Yogyakarta: Unit Penerbit.

Model, D., Pada, W., Gian, C. V, \& Autoservice, M. (2019). Rancang Bangun Sistem Informasi Pelayanan Jasa Home Service. 17(1), 17-21.

Pratama, I. P. A. E. (2014). Sistem Informasi dan Implementasinya. Bandung: Bandung Informatika.

Pt, P., Pikir, S., Utami, L. D., \& Hidayat, R. (2018). Pengolahan Data Keuangan Dengan Menggunakan Zahir Accounting 5 . 1. XVI(1), 99-106.

Romney, M. B., \& Steinbart, J. P. (2014). Sistem Informasi Akuntansi: Accounting Information
Systems (Edisi 13). Prentice Hall.

Sujarweni, V. W. (2015). Akuntansi Biaya. Yogyakarta: Pustaka Baru Press.

Sukamto, R. A., \& Shalahuddin, M. (2014). Rekayasa Perangkat Lunak Terstruktur dan Berorientasi Objek. Bandung: Informatika.

Sukamto, R. A., \& Shalahuddin, M. (2015). Rekayasa Perangkat Lunak Terstruktur dan Berorientasi Objek. Bandung: Informatika.

Susanto, A. (2017). Sistem Informasi Akuntansi: Memahami Konsep Secara Tersetruktur. Bandung: Linggar Jaya.

Tjiptono, F., \& Chandra, G. (2016). Pemasaran Jasa (Prinsip, Penerapan, Penelitian). Yogyakarta: Andi.

Yanto, R. (2016). Manajemen Basis Data Menggunakan MySQL. Yogyakarta: Deepublish.

1. Desain hak akses penggunaan sistem informasi akuntansi penjualan jasa service mobil

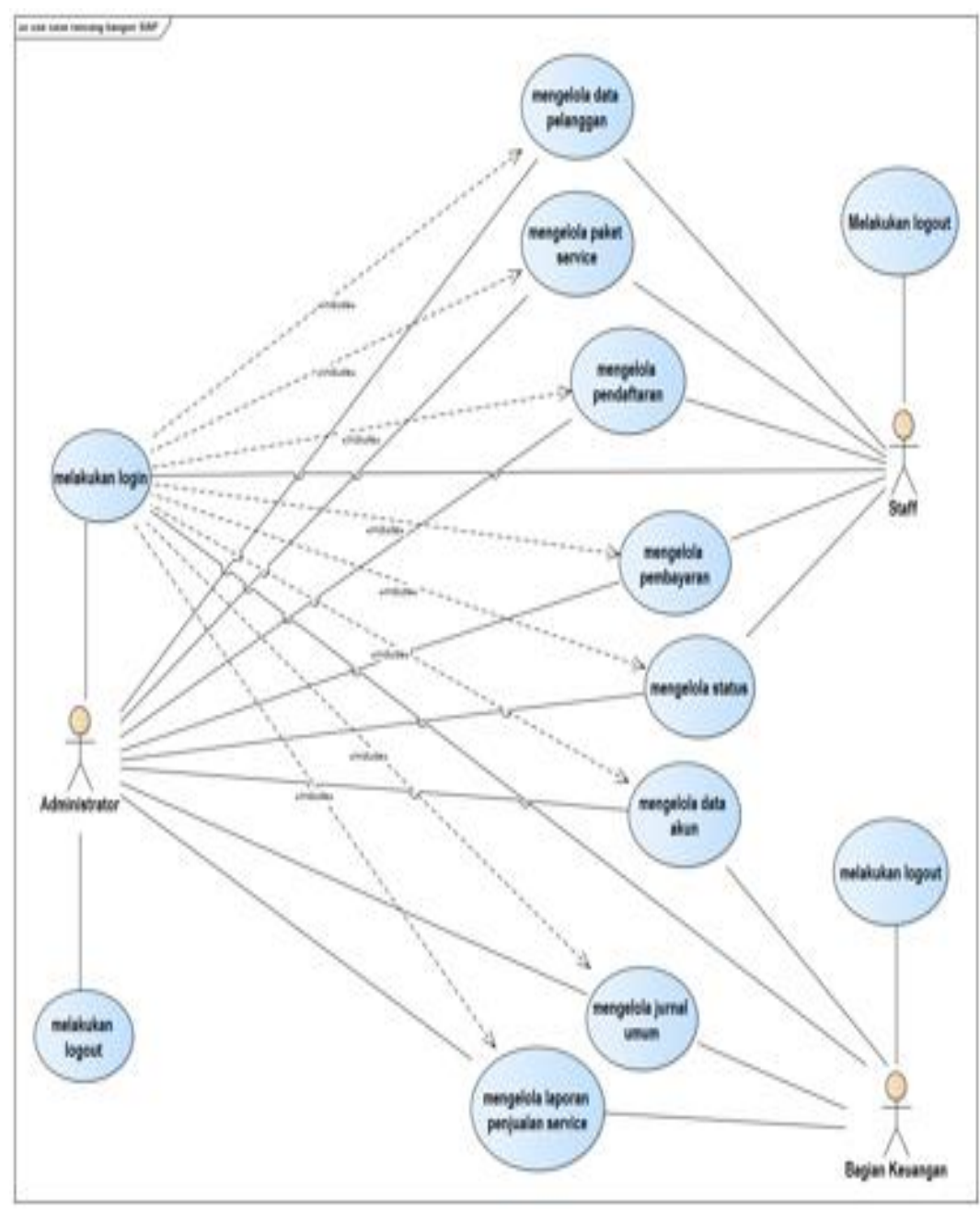

Sumber: Hasil Penelitian (2019)

Gambar 1. Desain Akses Pengguna Sistem 
2. Desain aktivitas sistem informasi akuntansi penjualan jasa service mobil.

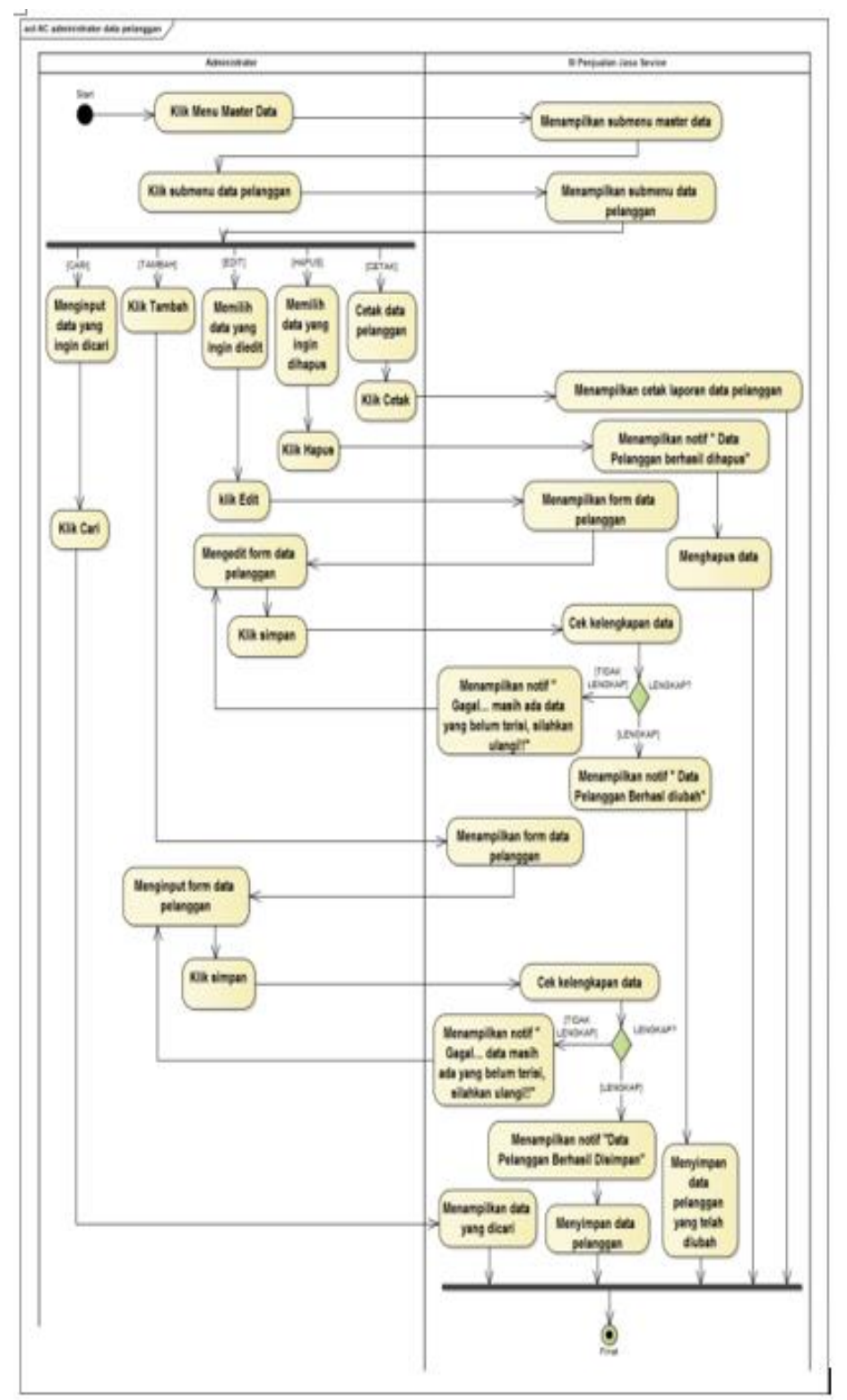

Sumber: Hasil Penelitian (2019)

Gambar 2. Rancangan Aktivitas Sistem 